\title{
Caracterização microbiológica de águas cinzas: eficiência de filtro com materiais não convencionais
}

\section{Erik Santos Passos ${ }^{1}$, Roseanne Santos de Carvalho $^{2}$ e Louise Francisca Sampaio Brandão ${ }^{3}$}

${ }^{1}$ Universidade Federal de Sergipe. Programa de Pós-Graduação em Desenvolvimento e Meio Ambiente. Campus São Cristóvão. São Cristóvão-SE, Brasil (CEP 49100-000). E-mail: erikspassos@gmail.com.

${ }^{2}$ Instituto Federal de Educação, Ciência e Tecnologia de Sergipe. Curso de Edificações. Campus Aracaju. Aracaju-SE, Brasil (CEP 49055-260).

${ }^{3}$ Instituto Federal de Educação, Ciência e Tecnologia de Sergipe. Curso de Engenharia Civil. Campus Aracaju. Aracaju-SE, Brasil. (CEP 49055-260).

Resumo. A escassez da água é uma problemática pré-existente da sociedade pós-moderna e na atualidade ganhou destaque principalmente nas regiões que sempre desfrutaram de abundantes recursos hídricos e passaram a sofrer com a falta do bem natural. São inúmeros os motivos que levam à escassez da água, perpassando desde a má distribuição territorial até a contaminação dos mananciais. Sendo assim, são necessárias técnicas e soluções como a reutilização de águas cinzas ou aproveitamento de águas pluviais para utilização em fins menos nobres, como lavagem de pisos, calçadas, rega de jardins, descargas sanitárias e irrigação. Com o intuito de aliar o reaproveitamento de resíduos à reutilização de águas cinzas, o artigo teve como objetivo uma caracterização microbiológica de coliformes totais e coliformes termotolerantes de águas cinzas tratadas por meio de um filtro composto de esponjas usadas, resíduos da construção civil e antracito, avaliando a eficiência do tratamento e visando a possibilidades de reuso não potável. As amostras de águas cinzas foram coletadas de um banheiro feminino no Instituto Federal de Sergipe, Campus Aracaju, Estado de Sergipe, Nordeste do Brasil, onde foram analisadas antes e após a passagem no filtro. As análises após filtragem apontaram reduções médias de 93,14\% na concentração de coliformes totais e de $90,42 \%$ de E. coli, caracterizando-o como um avanço para aliar o desenvolvimento à sustentabilidade.

Palavras-chave: Efluente; Reuso; Resíduos.

Abstract. Microbiological characterization of gray waters: Filter efficiency with non-conventional materials. Water scarcity is a pre-existing problem in postmodern society and nowadays it has gained prominence mainly in regions that have
Recebido

$02 / 05 / 2021$

Aceito

$26 / 07 / 2021$

Disponível on line

$31 / 07 / 2021$

Publicado

$31 / 08 / 2021$

Acesso aberto

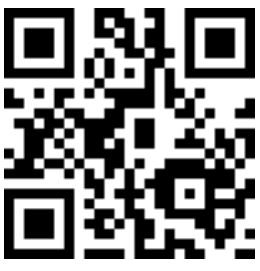

ORCID

(D) 0000-0002-2888-9126 Erik Santos Passos

(D) 0000-0001-6362-9277

Roseanne Santos de Carvalho 
always enjoyed abundant water resources and have suffered from the lack of natural good. There are countless reasons that lead to water scarcity, ranging from poor territorial distribution to the contamination of water sources. Therefore, techniques and solutions are necessary, such as the reuse of gray water or the use of rainwater for use in less noble purposes, such as washing floors, sidewalks, watering gardens, sanitary flushes and irrigation. In order to combine the reuse of residues with the reuse of gray waters, the article aimed at a microbiological characterization of total coliforms and thermotolerant coliforms of gray waters treated by means of a filter composed of used sponges, construction waste and anthracite, evaluating the efficiency of the treatment and aiming at possibilities of nonpotable reuse. The gray water samples were collected from a women's bathroom at the Federal Institute of Sergipe, Campus Aracaju, State of Sergipe, Northeast Brazil, where they were analyzed before and after passing the filter. The analyzes after filtering showed average reductions of $93.14 \%$ in the concentration of total coliforms and $90.42 \%$ of $E$. coli, characterizing it as an advance to combine development with sustainability.

Keywords: Effluent; Reuse; Waste.
D) $0000-0003-0263-0551$

Louise Francisca

Sampaio Brandão

\section{Introdução}

O pensamento de Jean Brunhes dentro da Geografia Humana dialoga fortemente com a escassez atual de recursos naturais, como a água, sua reflexão direta já previa uma economia agressiva consumindo os recursos não renováveis e renováveis em um curto espaço de tempo (Aguiar, 2010). Com uma análise global das ações de consumo pôde antecipar debates ambientais que acontecem atualmente, já que o fruto dessa economia definida pelo mesmo, nada mais é que o consumismo exacerbado, ou seja, a falta de limite entre a voraz força humana de explorar e a capacidade do meio ambiente se reestruturar e sobreviver.

O déficit de fontes naturais de água é que incentiva a busca por formas de evitar o desperdício e maximizar o uso da água, através da reutilização de águas cinzas para usos não potáveis, reduzindo a demanda dos mananciais e evitando uma possível contaminação das bacias por meio do descarte irregular desses resíduos líquidos. As águas cinzas são constituídas por efluentes provenientes de chuveiros, lavatórios, máquina de lavar roupa e por excluírem os efluentes dos vasos sanitários contém uma quantidade de resíduos inferior aos do esgoto doméstico, o que simplifica o tratamento.

Apesar de exigir um tratamento simplificado, critérios de segurança à saúde, aceitação por parte do usuário e viabilidade econômica devem ser respeitados no reuso de águas cinzas, e diversos fatores estão relacionados a esse atendimento. A qualidade da água de abastecimento é importante na qualidade do efluente bruto, pois juntamente com o uso a que se pretende destinar a água cinza tratada, deve influenciar na escolha da tecnologia de tratamento (Couto, 2012). A identificação e mensuração dos microrganismos existentes na água é crucial no que se diz respeito a saúde pública. A presença de alguns microrganismos como, coliformes totais e termotolerantes, são indícios de contaminação nos corpos d'água (Jordão e Pessoa, 2011). 
O filtro de areia é uma das tecnologias mais comuns de tratamento de águas cinzas (Allen et al., 2010). Na corrente pelo desenvolvimento sustentável, o filtro de areia é proposto por modelos modificados utilizando materiais não convencionais, como os resíduos da construção civil. A vantagem é agregar os resíduos da construção civil, como forma de minimizar os impactos ambientais negativos dessa prática, pois para Oliveira et al. (2020), os principais impactos causados ao meio ambiente e a sociedade urbana relacionados a geração desses resíduos, talvez seja originado da deposição irregular dos mesmos. 0 descarte impróprio de resíduos é um determinante do desequilíbrio da vida nas cidades ao causar o comprometimento da paisagem (poluição visual), degradação dos mananciais, obstrução dos sistemas de drenagem, proliferação de vetores causadores de doenças, assoreamento dos cursos d'água e dificultar a circulação de pessoas e veículos nas vias públicas.

A Lei no 12.305/2010 (Brasil, 2010) instituiu o Plano Nacional de Resíduos Sólidos (PNRS), que traz em suas diretrizes a problemática da gestão integrada de resíduos sólidos, sendo o conjunto de ações voltadas para a busca de soluções para os resíduos, de forma a considerar as dimensões política, econômica, ambiental, cultural e social sob a premissa do desenvolvimento sustentável (Reis et al., 2018). Com a regulamentação, a responsabilidade passa a ser integrada entre iniciativa privada, pública e sociedade geral, contemplando uma dimensão politicamente complexa ao integrar questões socioeconômicas às questões ambientais.

$\mathrm{Na}$ atual situação hídrica, torna-se fundamental a adoção de alternativas simples de tratamentos que possibilitem o reuso de águas, já que a prática implica positivamente em benefícios sociais, econômicos e ambientais. Como forma de minimizar os impactos ambientais negativos do descarte irregular dos resíduos, assim como garantir uma alternativa para reduzir a carga microbiológica desses efluentes, portanto, este artigo tem o escopo principal de fazer uma caracterização microbiológica de coliformes totais e coliformes termotolerantes de águas cinzas tratadas por meio de um filtro composto de esponjas usadas, resíduos da construção civil e antracito.

\section{Materiais e métodos}

\section{Caracterização do local de estudo}

0 estudo parte do método de abordagem hipotético-dedutivo, com a hipótese que o modelo de filtro em questão é capaz de reter microrganismos das águas cinzas. A partir daí, empregou-se uma coleta de dados simultâneos e sequenciais, utilizando uma metodologia experimental e controlada para refutar a hipótese e chegar a uma conclusão. Este trabalho foi composto pelas etapas de aquisição dos materiais, confecção e montagem do filtro, coleta de amostras, análise e comparação dos resultados. A pesquisa foi realizada no Instituto Federal de Sergipe, Campus Aracaju. Está situado na Avenida Engenheiro Gentil Tavares da Mota, 1166, Bairro Getúlio Vargas, Aracaju-SE.

As águas cinzas do estudo foram coletadas do banheiro feminino do ginásio de esportes do campus, justificado ao fato de ser o único banheiro com uma canaleta aberta de passagem das águas cinzas do banheiro. A coleta das amostras foi realizada seguindo os procedimentos descritos na norma ABNT NBR 9.898:1987 (ABNT, 1987) que regulamenta a coleta de efluentes líquidos. De acordo com pesquisas realizadas por Barros et al. (2016), na Instituição foi possível verificar que essas águas são as que possuem características mais críticas. Ao total foram coletadas quatro amostras de águas cinzas oriundas dos lavatórios e chuveiros do banheiro, nos períodos compreendidos na Tabela 1. 
Tabela 1. Amostragem das águas cinzas.

\begin{tabular}{|l|c|c|}
\hline Amostragem & Data & Volume coletado (L) \\
\hline Amostra 01 & $01 / 07 / 2019$ & 3,0 \\
\hline Amostra 02 & $08 / 08 / 2019$ & 3,0 \\
\hline Amostra 03 & $15 / 08 / 2019$ & 3,0 \\
\hline Amostra 04 & $22 / 08 / 2019$ & 3,0 \\
\hline
\end{tabular}

O filtro foi confeccionado em material acrílico com área externa $(10,0 \mathrm{~cm} \mathrm{x}$ $10,0 \mathrm{~cm}$ ) e altura de $100 \mathrm{~cm}$, usou-se uma tela de aço com o intuito de segurar a camada suporte, evitando desse modo, que os materiais da base escoassem durante a passagem da água. Os resíduos da construção civil foram recolhidos de caçambas estacionárias posicionadas no Município de Aracaju/SE, por onde a empresa de resíduos sólidos local faz o recolhimento desses resíduos. As esponjas foram adquiridas por meio de doação de estudantes do ensino superior do Instituto Federal de Sergipe, por se tratar de um material que é descartado com frequência no lixo. Os resíduos de pó de pedra foram recolhidos na própria instituição, no Laboratório de Materiais de Construção.

Sendo assim, foi necessário quebrar os resíduos da construção civil até o atendimento de uma granulometria de $4,8 \mathrm{~mm}$ para compor a camada suporte e grãos inferiores a $1,2 \mathrm{~mm}$ para compor o leito filtrante, para isso utilizou-se um soquete de compactação de solo para aplicar golpes em queda livre até que os resíduos estivessem quebradiços e em grãos menores. Logo após, foi realizada uma caracterização granulométrica por peneiramento, seguindo a norma ABNT NBR NM 248:2003 (ABNT, 2003), visando a identificar o tamanho dos grãos dos resíduos.

Já as esponjas foram cortadas em cubos para facilitar o acondicionamento dentro do leito de filtração. Posteriormente, todos os materiais foram lavados visando a retiradas de possíveis corpos estranhos, os granulares foram colocados em estufa por $24 \mathrm{~h}$ para que não houvesse umidade e fosse possível executar a montagem do filtro seguindo modelos de referência e a norma ABNT NBR 13.969:1997 (ABNT, 1997). 0 modelo piloto em escala de laboratório foi determinado englobando uma altura de leito filtrante de $52 \mathrm{~cm}$ e uma área interna de $100 \mathrm{~cm}^{2}$. As granulometrias das camadas estão representadas na Tabela 2.

Tabela 2. Granulometria das camadas do filtro.

\begin{tabular}{|l|c|c|c|}
\hline Camada & Altura $\mathbf{( c m )}$ & Material & Tamanho médio dos grãos \\
\hline Camada 01 & 2 & Resíduo cerâmico & $4,8 \mathrm{~mm}$ \\
\hline Camada 02 & 10 & Esponjas usadas & - \\
\hline Camada 03 & 10 & Resíduo cerâmico & 0,6 a 1,2 mm \\
\hline Camada 04 & 10 & Resíduo pó de pedra & 0,6 a $1,2 \mathrm{~mm}$ \\
\hline Camada 05 & 10 & Antracito & $1,2 \mathrm{a} 2,5 \mathrm{~mm}$ \\
\hline Camada 06 & 10 & Resíduo de concreto & $4,8 \mathrm{~mm}$ \\
\hline
\end{tabular}

A Figura 1 apresenta a configuração do filtro com as respectivas camadas preenchidas com os materiais não convencionais. Cabe destacar que o funcionamento do filtro se deu com taxas de aplicações semanais não constantes, em sentido descendente de fluxo, onde foram verificados registros de seu funcionamento como um todo. 


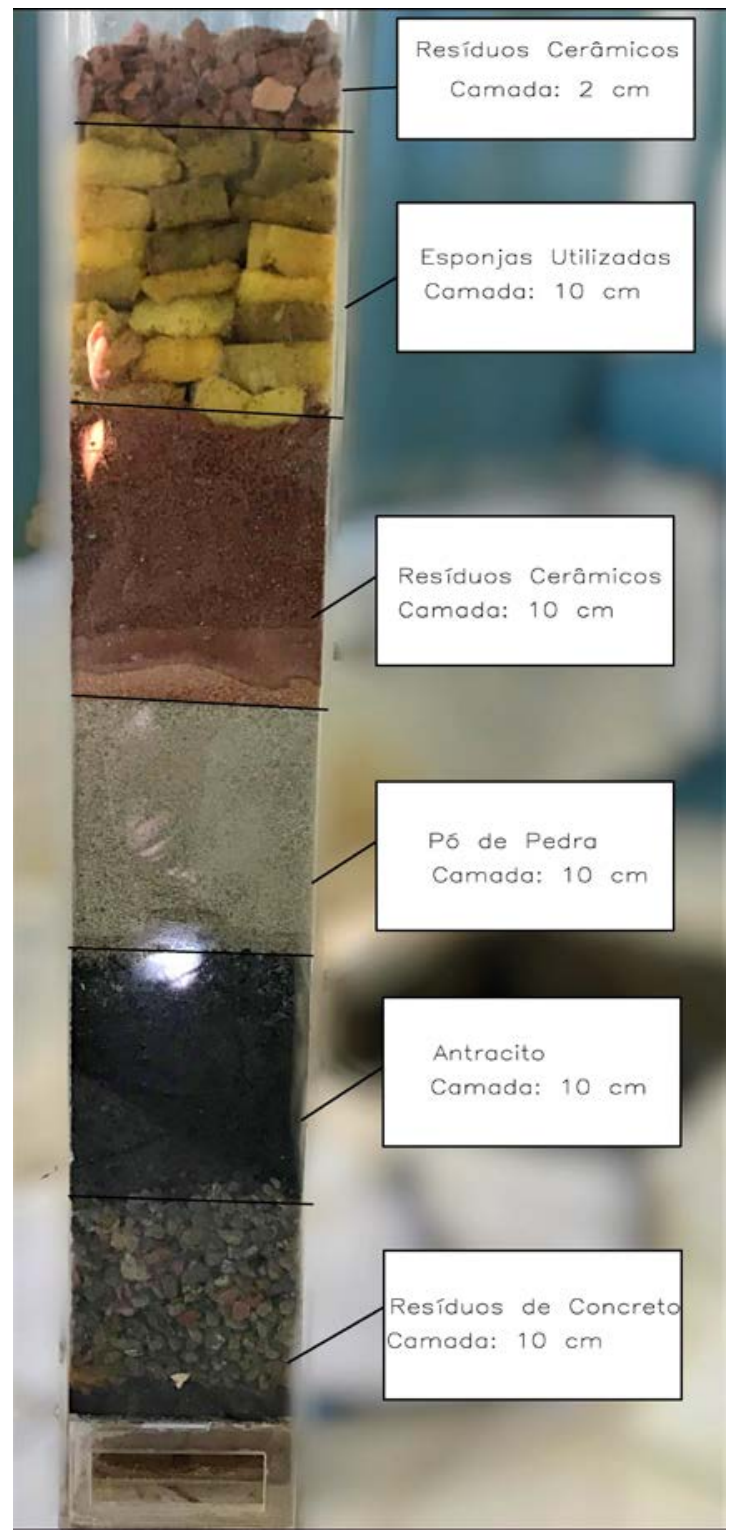

Figura 1. Representação do filtro com altura de camadas.

\section{Análises e técnicas utilizadas}

Na definição dos parâmetros qualitativos a serem analisados, analisou-se a norma ABNT NBR 13.969:1997 (ABNT, 1997) que oferece alternativas de procedimentos técnicos para o projeto, construção e operação de unidades de tratamento complementar e disposição final dos efluentes líquidos de tanques sépticos, com o intuito de verificar quais características são regulamentadas pela mesma, e assim, avaliá-las com o objetivo de sugerir possíveis destinações do efluente a ser tratado nesse estudo.

Os coliformes foram quantificados usando o Método Colilert/Colitag (Tabela 3), que detecta coliformes totais e E. coli, simultaneamente, em 24 h após incubação das amostras a $35^{\circ} \mathrm{C}-($ Brasil, 2013).

Todas as análises foram realizadas no Laboratório de Saneamento do Instituto Federal de Sergipe, campus Aracaju, seguindo rigores científicos para que os dados fossem confiáveis e apropriados para análise. 
Tabela 3. Parâmetros microbiológicos exigidos pela norma ABNT NBR 13.969:1997 (ABNT, 1997).

\begin{tabular}{|l|c|c|}
\hline Parâmetro & Método utilizado & Unidade \\
\hline Coliformes totais & \multirow{2}{*}{ Método Colilert/Colitag (Brasil, 2013) } & NMP/100 mL \\
\hline Coliformes termotolerantes &
\end{tabular}

Foram aplicados, semanalmente, 2,0 L o efluente coletado no filtro, resultando em efluente filtrado para comparação com as características do efluente bruto. Parâmetros operacionais, como taxa de filtração e vazão foram calculados de forma empírica, por meio da equação de vazão e taxa de filtração adotada por Von Sperling (2014), para caracterizar a filtração em regime descontínuo. A eficiência do filtro foi verificada de acordo com o modelo proposto por Von Sperling (2014) o qual está expresso na Equação 1.

$$
E=\frac{c_{o}-c_{e}}{c_{o}} \times 100
$$

\section{Equação 1}

Onde:

$\mathrm{E}=$ Eficiência de remoção (\%)

$\mathrm{C}_{\mathrm{o}}=$ Concentração afluente do poluente (UNID)

$\mathrm{C}_{\mathrm{e}}=$ Concentração efluente do poluente (UNID)

\section{Resultados e discussão}

\section{Parâmetros de operação do filtro}

Foram coletados dados experimentais acerca do funcionamento do tratamento, como a carga aplicada e o tempo de percolação do efluente, com isso obteve-se a vazão de funcionamento e a taxa de filtração. A Tabela 4 apresenta os valores encontrados de operação do sistema filtrante. Por se tratar de um filtro piloto em escala de laboratório, foi avaliado o seu potencial filtrante em aplicações semanais e pontuais, o caracterizando como um filtro em regime batelada ou descontinuo. Haja vista que dados como a manutenção, limpeza e mensuração da capacidade filtrante dos materiais não são objetivos desse trabalho, e sim somente verificar a influência do tratamento nas características da água cinza em estudo.

Tabela 4. Dados de operação do filtro.

\begin{tabular}{|l|c|}
\hline Parâmetro & Valor \\
\hline Carga aplicada & $0,002 \mathrm{~m}^{3}$ \\
\hline Tempo de percolação & $0,2 \mathrm{~h}$ \\
\hline Vazão de funcionamento & $0,01 \mathrm{~m}^{3} / \mathrm{h}$ \\
\hline Taxa de filtração & $1\left(\mathrm{~m}^{3} / \mathrm{m}^{2}\right) \times \mathrm{h}$ \\
\hline
\end{tabular}

Foram verificadas também as características visuais das águas cinzas, a Figura 2 mostra o efluente bruto após coleta no banheiro feminino do campus e o efluente após o tratamento de filtração proposto no estudo. É notável, que a filtração removeu parte dos sólidos presentes, promovendo um aspecto visual mais límpido. 


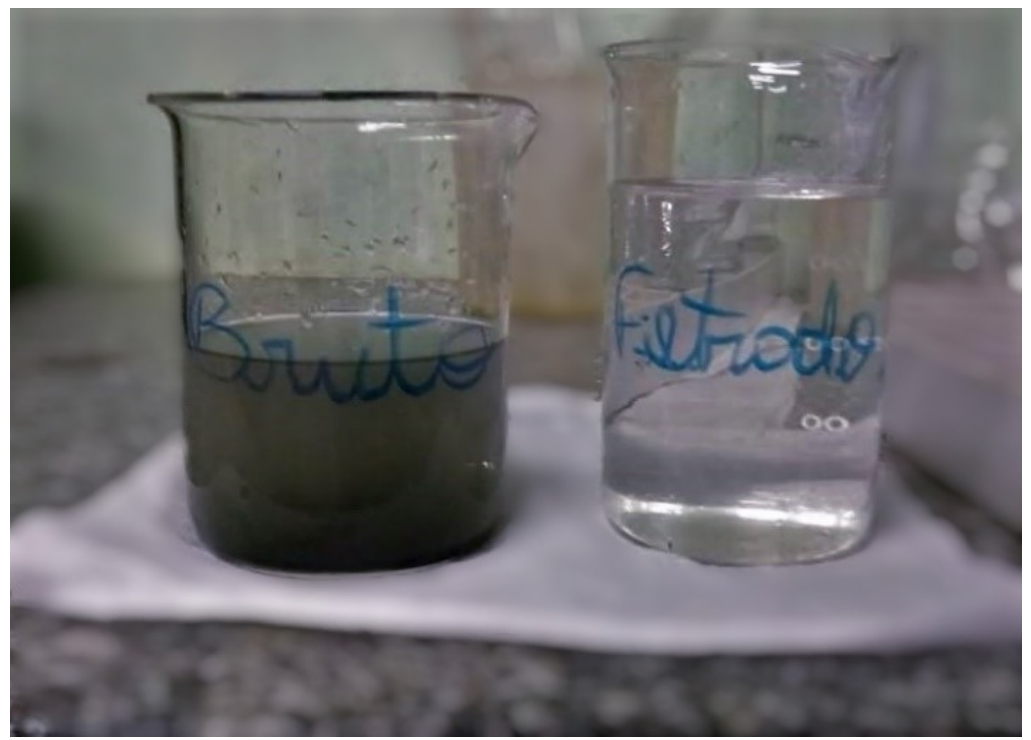

Figura 2. Aspecto visual do efluente antes e após a filtração.

\section{Caracterização microbiológica}

Os resultados obtidos acerca do parâmetro de coliformes totais no efluente bruto e tratado estão apresentados na Figura 3, com os valores por amostra e o valor médio.

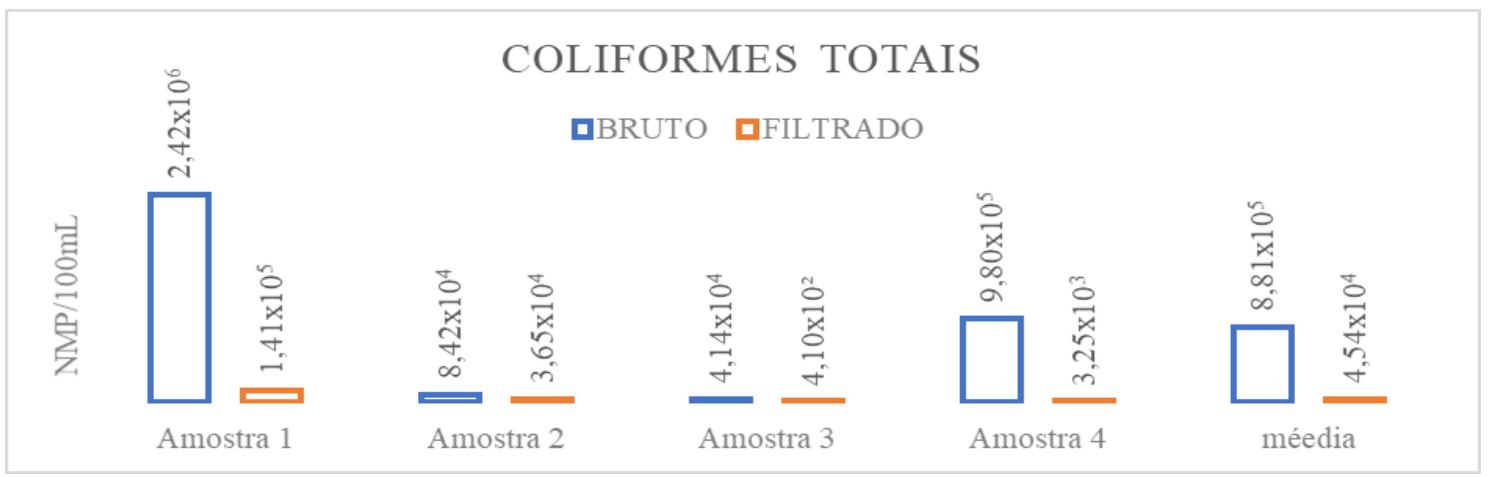

Figura 3. Concentração de coliformes totais presentes na água cinza.

De acordo com a Figura 3, percebe-se que o efluente, após passar pelo tratamento

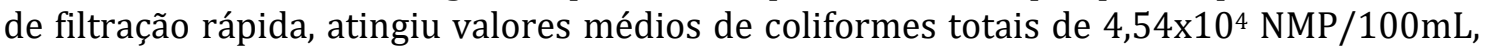
onde é possível afirmar que houve uma notável redução de seus valores pós tratamento, corroborando com a hipótese de que os materiais selecionados possuem propriedades de retenção de componentes microbiológicos presentes em águas cinzas. É importante ressaltar, que a eficácia dos materiais na filtração abre vertentes importantes para que se consiga alcançar um tratamento de baixo custo e sustentável, aproveitando resíduos que, descartados de forma inapropriada, serviriam de fonte de contaminação e degradação do meio ambiente.

Peprah et al. (2018), comentam que a composição das águas cinzas é um reflexo do estilo de vida e do tipo e quantidade de produtos químicos usados em limpeza, banhos e lavagem de roupas. A qualidade da água potável e o tipo de distribuição também afetam as características das águas cinzas, assim como haverá importantes variações na composição das águas cinzas dependentes da variação entre água consumida e água cinza gerada em 
cada atividade. Geralmente, esse tipo de água residual contém altas concentrações de matéria orgânica facilmente degradável, o que inclui nutrientes como os nitratos e seus derivados, fósforo e seus derivados, e algumas podem incluir microrganismos como coliformes termotolerantes, Salmonella, dentre outros.

Dentre os grupos de maior importância de microrganismos presentes na água cinza, destacam-se os coliformes termotolerantes, que tem como principal representante à E. coli, de origem exclusivamente fecal (Sarnaglia, 2014). Os coliformes termotolerantes, atribuído na pesquisa como a contagem de E. coli sofreram redução também, a densidade foi de 9,1 x $10 \mathrm{NMP} / 100 \mathrm{~mL}$, conforme a Figura 4. A redução proporcionada pelo filtro facilita a etapa de desinfecção que o efluente deve receber para o seu posterior reuso, haja vista que os filtros de areia não são normalmente utilizados com intuito de remoção microbiológica, mas, podem ajudar a reduzir a quantidade indesejada desses organismos.

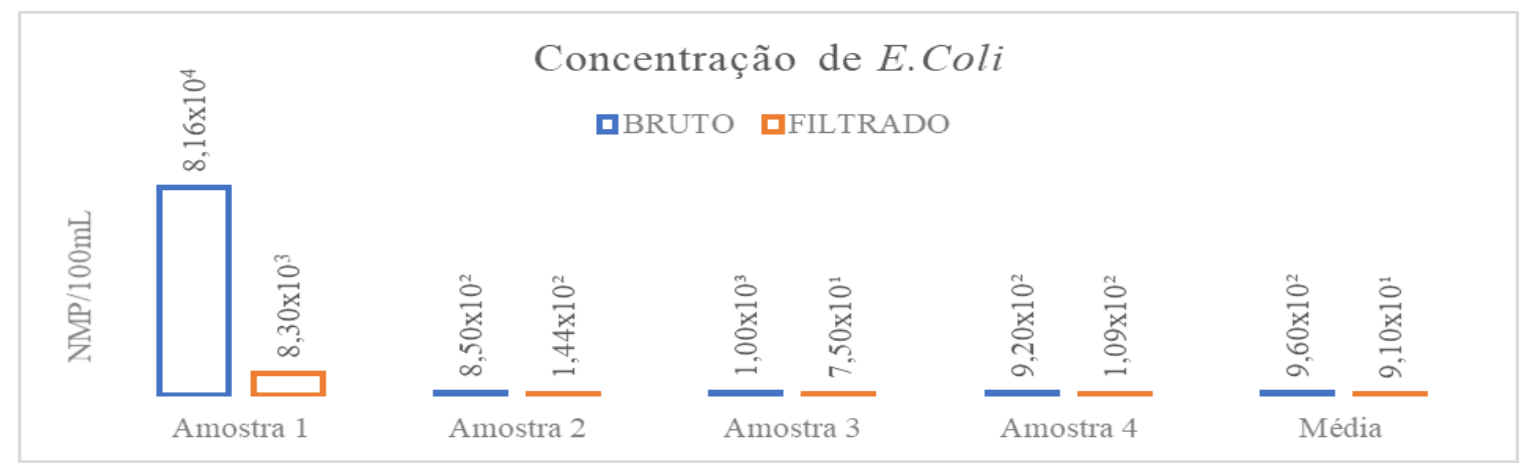

Figura 4. Concentração de E. coli presentes na água cinza.

Em seu trabalho coletando águas cinzas oriundas de lavatórios, chuveiros e máquina de lavar de um edifício universitário, Sarnaglia (2014) encontrou uma densidade média de coliformes totais presentes na água cinza próximos ao estudo em questão, segundo a Tabela 5. Já nos estudos realizados por Mendonça (2019) e Dantas et al. (2019), onde as amostras de águas cinzas advinham de somente um uso, lavanderia e pia de cozinha, respectivamente, os valores foram menores, devido ao fato do uso social dessas águas advir de atividades diferentes e isoladas.

Tabela 5. Valores encontrados em águas cinzas de estudos referenciais.

\begin{tabular}{|l|c|c|c|c|}
\hline Parâmetro & Este estudo & $\begin{array}{c}\text { Sarnaglia } \\
\mathbf{( 2 0 1 4 )}\end{array}$ & $\begin{array}{c}\text { Mendonça } \\
\mathbf{( 2 0 1 9 )}\end{array}$ & $\begin{array}{c}\text { Dantas et al. } \\
\mathbf{( 2 0 1 9 )}\end{array}$ \\
\hline Coliformes totais $(\mathrm{NMP} / 100 \mathrm{~mL})$ & $8,81 \times 10^{5}$ & $6,3 \times 10^{4}$ & $1,12 \times 10^{3}$ & $2,4 \times 10^{3}$ \\
\hline E. coli $(\mathrm{NMP} / 100 \mathrm{~mL})$ & $9,6 \times 10^{2}$ & $5,86 \times 10^{3}$ & - & - \\
\hline
\end{tabular}

\section{Eficiência do tratamento}

O filtro obteve uma notável eficiência na remoção de coliformes totais, com uma média de $87,36 \%$ de remoção. Para se definir o que exatamente levou essas elevadas reduções, cabe uma caracterização dos materiais granulares por meio de Microscopia Eletrônica de Varredura (MEV) para visualizar a morfologia desses materiais e entender sua capacidade de retenção de sólidos. Mendonça (2019) utilizou como tratamento somente o filtro de areia e obteve uma remoção de $26,9 \%$ dos coliformes totais, enquanto que ao utilizar coagulação, floculação, sedimentação seguido de filtro de areia e filtro de carvão ativado, atingiu a eficiência de 80,9\%. Já Sarnaglia (2014) ao utilizar wetland 
vertical pôde constatar uma redução de $81 \%$ dos coliformes totais num tempo de detenção hidráulica de 3 dias, enquanto que remoção de E. coli foi de $66 \%$ para o mesmo tempo.

Igualmente aos coliformes totais, o tratamento com resíduos não convencionais obteve atenuante desempenho com a redução de E. coli, com uma média de 90,52\%. Vale reiterar que referidos contaminantes são os mais perigosos para os seres humanos, já que causam problemas de saúde devido a origem fecal, o que recai na importância de removêlos para o posterior reuso.

Santana (2013) obteve uma remoção média de E. coli de 99,95\% após tratamento combinado de filtro com serragem de madeira e filtro com carvão ativado, ou seja, um tipo de tratamento não convencional utilizando a serragem, combinada com uma técnica conhecida que é a filtração com carvão. A incorporação desses resíduos, associados a técnicas já conhecidas tradicionalmente, engloba um futuro promissor para o avanço no tratamento de efluentes e o desenvolvimento de forma sustentável.

\section{Potencial de reuso e importância socioambiental}

Avaliando os valores médios dos parâmetros microbiológicos da água cinza filtrada com os exigidos pela norma ABNT NBR 13.969:1997 (ABNT, 1997), pode-se concluir, conforme a Tabela 6, que o efluente tratado com uma única etapa de tratamento se enquadra em todas classes da referida norma e pode ser reutilizado em lavagem de carros, lavagens de calçadas, irrigação de jardins, descargas sanitárias e em pomares, cereais, forragens, pastagem de gados e outros cultivos através de escoamento superficial ou por sistema de irrigação pontual. Cabe destaque para o fato dessa análise ser apenas em relação aos parâmetros microbiológicos, deve-se atentar aos parâmetros físicos e químicos para que seja possível fazer o reuso seguindo a legislação.

Tabela 6. Qualidade de água por classe de uso não potável.

\begin{tabular}{|c|c|c|}
\hline Classe 1 & $\begin{array}{l}\text { Lavagem de carros e outros usos que } \\
\text { requerem o contato direto do usuário } \\
\text { com a água, com possível aspiração de } \\
\text { aerossóis pelo operador, incluindo } \\
\text { chafarizes. }\end{array}$ & $\begin{array}{l}\text { Turbidez inferior a } 5 \mathrm{NTU}, \text { coliforme } \\
\text { termotolerante inferior a } 200 \mathrm{NMP} / 100 \mathrm{~mL} \text {; } \\
\text { sólidos dissolvidos totais inferiores a } 200 \\
\mathrm{mg} / \mathrm{L} \text {; pH entre 6,0 e 8,0; cloro residual entre } \\
0,5 \mathrm{mg} / \mathrm{L} \mathrm{e} 1,5 \mathrm{mg} / \mathrm{L} \text {. }\end{array}$ \\
\hline Classe 2 & $\begin{array}{l}\text { Lavagens de pisos, calçadas e irrigação } \\
\text { dos jardins, manutenção dos lagos e } \\
\text { canais para fins paisagísticos, exceto } \\
\text { chafarizes. }\end{array}$ & $\begin{array}{l}\text { Turbidez inferior a } 5 \mathrm{NTU} \text {, coliforme } \\
\text { termotolerante inferior a } 500 \mathrm{NMP} / 100 \mathrm{~mL} \text {, } \\
\text { cloro residual superior a } 0,5 \mathrm{mg} / \mathrm{L} \text {. }\end{array}$ \\
\hline Classe 3 & $\begin{array}{l}\text { Reuso nas descargas dos vasos } \\
\text { sanitários. }\end{array}$ & $\begin{array}{l}\text { Turbidez inferior a } 10 \text { NTU, coliformes } \\
\text { termotolerantes inferiores a } 500 \text { NMP } / 100 \\
\text { mL. }\end{array}$ \\
\hline Classe 4 & $\begin{array}{l}\text { Reuso nos pomares, cereais, forragens, } \\
\text { pastagens para gados e outros cultivos } \\
\text { através de escoamento superficial ou } \\
\text { por sistema de irrigação pontual. }\end{array}$ & $\begin{array}{l}\text { Coliforme termotolerante inferior a } 5.000 \\
\text { NMP/100 mL e oxigênio dissolvido acima de } \\
\text { 2,0 mg/L. }\end{array}$ \\
\hline
\end{tabular}

Fonte: ABNT (1997).

Ao se debater o viés sustentável dentro de ações cotidianas, fica claro o quão essas tecnologias podem contribuir para um desenvolvimento sustentável nas relações sociedade e natureza. A urbanização trouxe consigo mudanças que acarretaram, atualmente, numa degradação das florestas e rios, afetando diretamente esses recursos essências para a vida. A mudança nos cursos dos rios, a poluição de suas nascentes e seu 
assoreamento são consequências advindas pela falta de preocupação sustentável, uma visão ultrapassada do homem moderno que corrobora com os diversos problemas enfrentados pela preservação desses bens naturais.

0 relatório da ONU (2015) enfatiza que o desenvolvimento sustentável e a gestão integrada dos recursos hídricos são cruciais para alcançar os objetivos sociais, econômicos e ambientais. 0 documento destaca a importância da implementação de tais programas e projetos, assim como da promoção de parcerias e do envolvimento de diversas partes interessadas para se cumprir a Agenda 2030 para o Desenvolvimento Sustentável, com foco na implementação do Objetivo do Desenvolvimento Sustentável (ODS) 6 de "assegurar a disponibilidade e gestão sustentável da água e saneamento para todos". Assim, como forma de gerir de forma sustentável é que se busca essas tecnologias, visando a uma aplicação desses objetivos e promovendo uma participação integrada de gestão ambiental.

Os impactos socioambientais das ações de reuso são geralmente positivos, já que os cursos de água têm sido reféns do descarte irregular de resíduos sólidos e líquidos, sofrendo dessa forma depreciação na qualidade desse recurso natural. Para Santos et al. (2018), o reuso de efluentes tratados se apresenta como uma importante ferramenta de uso racional de água no âmbito da gestão de recursos hídricos. Essa prática, além de mitigar os impactos no meio ambiente, decorrentes do lançamento de efluentes, reduz a captação de água dos mananciais permitindo maior disponibilidade hídrica para os diversos fins.

0 aproveitamento dos resíduos aliado à redução do consumo de água por meio do reuso de seus efluentes altera também o modo de viver da sociedade e impacta em uma economia no valor da conta de água, já que utilizando suas águas residuais para rega de jardins e descargas sanitárias efetiva-se uma redução no consumo de água potável advindo das empresas distribuidoras. As ações decorrentes da ambientalização curricular têm aumentado a difusão das práticas de gestão ambiental e desenvolvimento sustentável, apesar da prática de reuso ainda ser debatida devido à sua resistência pela aceitabilidade social, cabe fomentar discussões entre Instituições, poder público e comunidade para que seja explicitado os impactos positivos que essas medidas podem oferecer.

\section{Conclusões}

O funcionamento do tratamento constituído por esponjas descartadas e resíduos da construção civil mostrou ser um sistema de operação simples e que não apresentou problemas operacionais. No que diz respeito aos resultados obtidos, notou-se resultados satisfatórios e superiores a outros estudos e técnicas de tratamento de águas cinzas. Os materiais escolhidos funcionaram como meio filtrantes e foram capazes de reduzir componentes indesejados presentes no efluente, o que leva a concluir que podem ser utilizados como substitutos dos materiais convencionais, areia e brita. A hipótese inicial do trabalho foi atendida e pôde-se notar que mesmo sendo caracterizada como uma água cinza com notável quantidade de coliformes totais e termotolerantes, os materiais não convencionais exerceram suas funções filtrantes e adsorventes e possibilitaram reduções acima de $90 \%$.

A alta eficiência na remoção microbiológica no sistema colabora com o processo posterior de desinfecção do efluente para sua reutilização em finalidades que haja contato humano com essas águas. 0 filtro removeu em média 93,14\% dos coliformes totais e $90,42 \%$ da concentração de E. coli presentes nas águas cinzas. Logo, efetiva-se a viabilidade dele para tratamentos que pretendem reduzir componentes microbiológicos. Levando-se em consideração os objetivos do estudo, o efluente filtrado poderia ser utilizado em todas as classes de reuso da norma ABNT NBR 13.969:1997 (ABNT, 1997). Além do mais, pode-se discutir os impactos positivos para beneficiar a sociedade e o meio 
ambiente, oferecendo uma alternativa de reutilização de resíduos que podem ser descartados de forma imprópria afetando os ecossistemas e proporcionando uma redução no uso de água potável para atividades com finalidades menos nobres.

Através de união e apoio a propostas científicas de projetos que visem a promover o bem estar social e a preservação dos recursos naturais, é possível pensar em uma gestão ambiental pública aliada à pesquisa científica para conceber à sociedade alternativas e exemplos para atingir os Objetivos do Desenvolvimento Sustentável. Aproximando os enfoques de legislação, os impactos antrópicos do homem aos recursos hídricos, a carência social de tecnologias democráticas e permeando a influência na economia, pode-se obter de forma interdisciplinar uma aproximação ao desejado conviver sustentável.

\section{Conflito de interesses}

Os autores declaram não haver conflito de interesses.

\section{Referências}

ABNT - Associação Brasileira de Normas Técnicas. ABNT NBR 9.898:1987 - Preservação e técnicas de amostragem de efluentes líquidos e corpos receptores. Rio de Janeiro: ABNT, 1987.

ABNT - Associação Brasileira de Normas Técnicas. ABNT NBR 13.969:1997 - Tanque sépticos - Unidades de tratamento complementar e disposição final dos efluentes Projeto, construção e operação. Rio de Janeiro: ABNT, 1997.

ABNT - Associação Brasileira de Normas Técnicas. ABNT NBR NM 248:2003 Agregados - Determinação da composição granulométrica. Rio de Janeiro: ABNT, 2003.

Aguiar, T.C.A concepção sociedade/natureza redimida pela questão ambiental contemporânea. Geo UERJ, v. 2, n. 21, p. 79-98, 2010. https://doi.org/10.12957/ geouerj.2010.1477

Allen, L.; Christian-Smith, J.; Palaniappan, M. Overview of greywater reuse: The potential of greywater systems to aid sustainable water management. Oakland: Pacific Institute, 2010. Disponível em: <https://pacinst.org/wp-content/uploads/2010/11/greywater_ overview3.pdf>. Acesso em: 20 out. 2020.

APHA - American Public Health Association. Standard methods for the examination of water and wastewater. 22. ed. Washington: APHA/AWWA/WEF, 2012.

Andrade, M. C. Geografia, ciência da sociedade: uma introdução à análise do pensamento geográfico. São Paulo: Atlas, 1987.

Barros, J. P. R.; Carvalho, C. L.; Marques, K. R.; Brandão, L. S.; Goes, J. R.; Silva, F. V. Projeto de reuso de água cinza no IFS, Campus Aracaju, por meio de recirculação nos banheiros e irrigação de jardins, com seus aspectos econômicos e qualitativos. Anais do Congresso de Iniciação Científica, Aracaju, IFS, p. 1-9, 2016.

Brasil. Lei no 12.305, de 2 de agosto de 2010. Institui a Política Nacional de Resíduos Sólidos; altera a Lei no 9.605, de 12 de fevereiro de 1998; e dá outras providências. Disponível em: <http://www.planalto.gov.br/ccivil_03/_ato2007-2010/2010/lei/l12305. htm>. Acesso em: 16 ago. 2020.

Brasil. Fundação Nacional de Saúde. Manual prático de análise de água. 4 ed. Brasília: FUNASA, 2013. 
Couto, E. A. Avaliação do reuso de águas cinza em ambientes aeroportuários. Viçosa: Universidade Federal de Viçosa, 2012. (Dissertação de mestrado).

Dantas, P. R.; Chaves, M. T. L.; Cavalcante, D. M.; Albuquerque, W. G.; Medeiros, W. P.; Bezerra, A. M. S. Reuso de água cinza tratada em sistema de alagado construído com resíduos da construção civil. Revista Verde de Agroecologia e Desenvolvimento Sustentável, v. 14, n. 1, p. 62, 2019.

Jordão, E. P.; Pessoa, C. A. Tratamento de esgotos domésticos. 6 ed. Rio de Janeiro: ABES, 2011.

Mendonça, K. P. L. Tratamento de águas cinza provenientes de lavanderias visando ao reuso. Palmas: Universidade Federal do Tocantins, 2019. (Dissertação de mestrado profissional).

Oliveira, L. J. C.; Soares, M. C. B.; Quaresma, W. M. G.; Adorno, A. L. C. Gestão de resíduos: uma análise sobre os impactos da geração de rejeitos na construção civil. Brazilian Journal of Development, v. 6, n. 5, p. 24447-24462, 2020. https://doi.org/10.34117/ bjdv6n5-047

ONU - Organização das Nações Unidas. Transforming our world: The 2030 Agenda for Sustainable Development. New York: ONU, 2015. Disponível em: $<$ https://sustainabledevelopment.un.org/post2015/transformingourworld>. Acesso em: 28 out. 2020.

Peprah, M. O.; Acheampong, M. A.; Vries, N. K. Greywater characteristics, treatment systems, reuse strategies and user perception: A review. Water, Air, \& Soil Pollution, v. 229, n. 8, p. 2-16, 2018. https://doi.org/10.1007/s11270-018-3909-8

Reis, D.; Friede, R.; Lopes, F. H. P. Política Nacional de Resíduos Sólidos (Lei no 12.305/2010) e educação ambiental. Revista Interdisciplinar do Direito, v. 14, n. 1, p. 99-111, 2018. Disponível em: <https://revistas.faa.edu.br/index.php/FDV/article/ view/251>. Acesso em: 13 jul. 2020.

Santana, E. A. Desenvolvimento de um sistema de filtragem para tratamento de água cinza visando ao seu reuso. Viçosa: Universidade Federal de Viçosa, 2013. (Dissertação de mestrado).

Santos, A. S. P.; Lima, M. A. M.; Ramos, L. T. A; Pereira, C. B.; Soares, S. R. A.; Melo, M. C. Capacidade de reuso de efluentes de estações de tratamento de esgoto na Bacia Hidrográfica do Paraíba do Sul. Semioses, v. 12, n. 3, p. 16-33, 2018.

Sarnaglia, S. A. A. Desempenho de um wetland vertical aplicado ao tratamento do efluente de um filtro anaeróbio em uma estação de tratamento de águas cinzas claras visando ao reuso não potável em edificações residenciais. Vitória: Universidade Federal do Espírito Santo, 2014. (Dissertação de mestrado).

Von Sperling, M. Introdução à qualidade das águas e ao tratamento de esgotos. 3. ed. Belo Horizonte: UFMG, 2014.

Informação da Licença: Este é um artigo Open Access distribuído sob os termos da Licença Creative Commons Attribution, que permite uso irrestrito, distribuição e reprodução em qualquer meio, desde que a obra original 
seja devidamente citada. 